DE LOS VIDEOJUEGOS

\section{AL CURRÍCULUM}

ESCOLAR

\section{Las estrategias del profesorado}

\section{María Ruth García Pernía}

\section{Investigadora}

Grupo de Investigación Imágenes, Palabras e Ideas. Departamento de Psicopedagogía. Universidad de Alcalá. Pza. San Diego, s/n - 28801 Alcalá de Henares, Madrid (España) - Email: mruth.garcia@uah.es

\section{Sara Cortés Gómez}

\section{Investigadora}

Grupo de Investigación Imágenes, Palabras e Ideas. Departamento de Psicopedagogía. Universidad de Alcalá. Pza. San Diego, s/n - 28801 Alcalá de Henares, Madrid (España) - Email: sara.cortesg@uah.es

\section{Rut Martínez Borda}

\section{Investigadora}

Grupo de Investigación Imágenes, Palabras e Ideas. Departamento de Psicopedagogía. Universidad de Alcalá. Pza. San Diego, s/n - 28801 Alcalá de Henares, Madrid (España) - Email: rut.martinez@uah.es
Palabras clave

Videojuegos comerciales, estrategias, currículum, etnografía, enseñanzaaprendizaje, Educación Secundaria,

Lengua-Literatura y Biología

Key Words

Commercial video games, strategies, curriculum, ethnography, learningteaching, Secondary school,

Language-Literature and Biology

\section{Abstract}

This article demonstrates the use of commercial video games from an educational standpoint, based on the strategies used by teachers to introduce them in their classrooms. The aim is to reflect on the special features of each game and how each teacher is facing its application connects to the academic curriculum. We will analyze the different strategies of teaching and

learning generated by teachers to connect each of the games with the educational context. The experience described in this paper is part of the video game project "Commercial Video Games in Secondary Education" (www.aprendeyjuegaconea. com) performed during the 2008/2009 academic year and with the colaboration of Electronic Arts with its Responsability Program

Corporate, Secondary School from Madrid and Culture, Technology and New Literacies Research Group from University of Alcalá. 


\section{Resumen}

Este artículo muestra el uso de los videojuegos comerciales desde un punto de vista educativo, partiendo de las estrategias seguidas por el profesorado para introducirlos en sus aulas. El objetivo es reflexionar sobre qué características presenta cada tipo de videojuego y cómo cada docente se enfrenta a su uso conectándolo con el currículum académico. Para ello se analizarán las diferentes estrategias de enseñanza-aprendizaje generadas por el profesorado para conectar cada uno de los videojuegos con el contexto educativo. La experiencia que se describe en este trabajo, se enmarca dentro del proyecto de videojuegos "Videojuegos comerciales en las aulas de Secundaria” (www.aprendeyjuegaconea.com), realizado durante el curso 2008/2009 y donde colaboran la empresa Electronic Arts desde su Programa de Responsabilidad Social Corporativa, un centro de Educación Secundaria de la Comunidad de Madrid y el Grupo de Investigación Imágenes, Palabras e Ideas (http://uah-gipi.org) de la Universidad de Alcalá. Desde una perspectiva etnográfica, se analiza cómo el videojuego Spore fue introducido en la asignatura de Biología y, por otra parte, cómo Harry Potter se convirtió en un recurso para el profesor de Lengua y Literatura. Se trataba de conectar los contenidos curriculares de sus asignaturas con el currículum oculto de los juegos.

\section{Introducción}

Después de cuarenta años de existencia, los videojuegos finalmente han comenzando a recibir atención especializada por parte de los educadores. Poco a poco se han hecho hueco en los estudios relacionados con la enseñanza y el aprendizaje. Esto se debe en parte, a que las nuevas generaciones de escolares están creciendo con los videojuegos, los conocen, comparten sus historias, viven sus mundos y se relacionan mediante ellos. Todo ello ha provocado que este nuevo medio obtenga un lugar importante en nuestra cultura y también en la educación.

¿Qué posibilidades educativas ofrecen los retos que esconden los videojuegos tras sus pantallas?
¿Qué trabajo pueden desarrollar los profesores a partir de su uso? Descubrimos que las características que poseen estos medios, muestran un contenido oculto que permite ser conectado con ciertas asignaturas escolares: como es el caso de Spore con biología y Harry Potter con Lengua y literatura. Partiendo de esta idea, el objetivo que marca este trabajo es mostrar cómo pueden ser introducidos los juegos en las aulas, las posibilidades y características que ofrecen y cómo los profesores son capaces de conectarlos con sus contenidos teóricos.

Desde esta perspectiva se ha trabajado con dos tipos de juegos: Spore (juego de simulación y estrategia) y Harry Potter y la Orden 
del Fénix (centrado en las aventuras), que posibilitaban crear situaciones diferentes de enseñanza-aprendizaje en las aulas. Cada uno de ellos se ha utilizado en contextos diferentes y con objetivos distintos, aspectos que marcaron el desarrollo de dos de los talleres realizados en el centro de Educación Secundaria durante el curso escolar 2008-2009. Por un lado, tomamos como referencia el videojuego Spore y el taller realizado en el aula de $4^{\circ}$ ESO. El objetivo de la profesora era conectar este medio con la asignatura de Biología, transportando a los alumnos a un mundo virtual que les permitía aprender en primera persona y de forma práctica, las teorías de la evolución de las especies, la superviviencia, etc. En el caso del taller de Harry Potter en $1^{\circ}$ ESO, el profesor de Len- gua y Literatura motivó a su alumnado a profundizar en el juego para posteriormente realizar producciones literarias vinculadas a sus experiencias vividas. Como vemos, lo que comenzó siendo el manejo de una tecnología poco convencional para los docentes, pronto se convirtió en una actividad con un enorme potencial educativo al conseguir conectar con el contenido curricular de las asignaturas que impartían.

Tomando como punto de partida estas conexiones educativas generadas entre dichos juegos y el contenido de sus materias, el objetivo de este artículo es analizar y mostrar las estrategias utilizadas por ambos docentes con el alumnado, cuando introdujeron los videojuegos en sus clases convirtiéndolos en un instrumento educativo.

\section{Objetivos}

A lo largo de numerosas investigaciones se ha tratado de analizar cómo los videojuegos pueden ser introducidos en las aulas de los centros educativos. Prueba de ello son algunos de los estudios realizados por el grupo de investigación GIPI (Lacasa \& GIPI 2007, 2009). Para definir los objetivos, por tanto, debemos contextualizar este trabajo tomando como referente la meta que siempre guía nuestras investigaciones: Diseñar escenarios educativos innovadores que contribuyan al desarrollo de las nuevas habilidades en la sociedad del siglo XXI.
Por esta razón, se han usado los videojuegos comerciales desde una perspectiva educativa identificando las diversas estrategias que pueden surgir a la hora de introducirlos en las aulas. A partir de esta idea, se pueden concretar los siguientes objetivos específicos:

1. Descubrir las características más importantes que definen el contenido y el diseño de los videojuegos de simulación y aventura.

Mostrar las diferentes estrategias educativas utilizadas por los dos docentes, que imparten las asignaturas de Biología y Lengua 
y Literatura y, que participan en esta expetes, Spore y Harry Potter respectivamente. riencia con dos videojuegos muy diferen-

\section{Metodología}

Este trabajo está basado en una metodología propia del estudio de casos, combinada con la utilización y técnicas procedentes de la etnografía (Hammersley \& Atkinson, 2007; Atkinson, Coffey, Delamnont, Lofland \& Lofland, 2001; Castanheira, Crawford, Dixon \& Green, 2001). El interés reside en observar lo que sucede en situaciones naturales, en este caso, saber qué ocurre en las aulas que estamos investigando sin introducir modificaciones que perturban la marcha de la actividad. Por tanto, su validez se fundamenta en la descripción detallada de los casos en los que se puede explicar cómo las personas atribuyen sentido a su actividad en contextos socioculturales definidos. De esta forma, partimos de una observación de la situación que permite describir y comprender cuáles fueron los procesos y estrategias seguidas por los docentes en sus clases cuando usaron los videojuegos comerciales.

Debemos destacar que las conversaciones que tuvieron lugar en el aula, analizadas bajo el modelo clásico de análisis del discurso (Gee, 2005), se han revelado como un potente instrumento para conocer el proceso de construcción en las representaciones mentales que los alumnos alcanzaron. Descubriendo de este modo, las co- nexiones generadas por los estudiantes entre sus materias escolares y el potencial de los videojuegos, comprendiendo así los procesos de aprendizaje que se llevan a cabo en el aula cuando dichos instrumentos están presentes.

Los materiales recogidos en los dos talleres y que aquí se han analizado, han sido claves para poder comprender e interpretar el proceso de trabajo y las estrategias seguidas por parte del profesor. Nos estamos refiriendo a múltiples medios como grabaciones de audio y vídeo, fotografías tomadas en el aula, registros narrativos cotidianos realizados por el investigador (sumarios) de cada una de las sesiones y los documentos escritos por el alumnado. Generando, con todo ello, una visión más completa de lo sucedido en ambos talleres.

\section{Los videojuegos}

No debemos pasar por alto los instrumentos que fueron la clave del desarrollo de los talleres: los videojuegos. Como se ha mencionado anteriormente nos centraremos en los videojuegos Spore y Harry Potter y la Orden del Fénix.

Spore: Es un videojuego de estrategia que exige al jugador resolver problemas con diferentes niveles de dificultad y, en ocasiones, implican un alto grado de planifica- 
ción enfocado a elegir la más adecuada a la situación planteada. En este caso, Spore recrea un viaje épico que llevará al origen y la evolución de la vida, el desarrollo de civilizaciones, e incluso se podrá viajar por el espacio exterior. El jugador puede crear su propio universo personal con diferentes seres vivos que evolucionan en el mundo virtual. Estas posibilidades de creación permiten descubrir el valor de la toma decisiones y su conexión con teorías de la evolución de las especies.

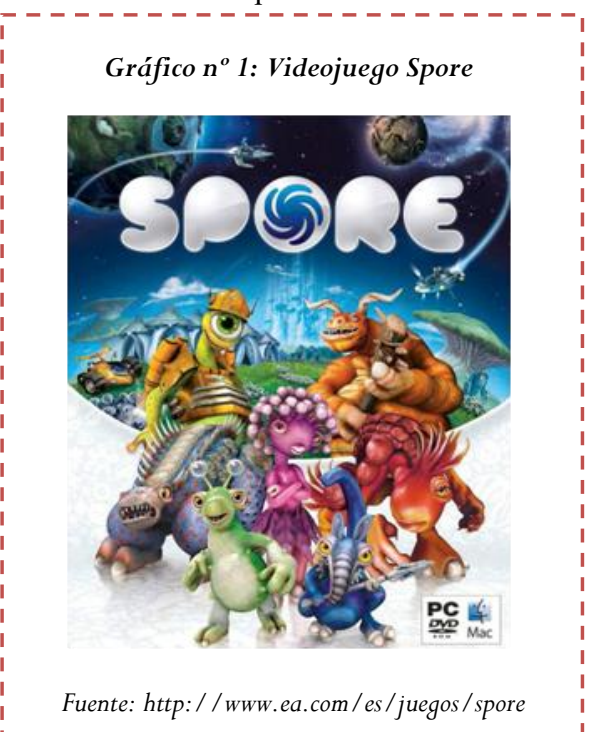

En cambio, los juegos de aventuras ofrecen nuevas formas de contar historias. En ellos los personajes, los objetos, el tiempo y el espacio se combinan para hacer atractiva la aventura de un héroe, convertido en personaje virtual. Un buen ejemplo de este tipo de juegos es Harry Potter y la Orden del Fénix. Harry debe completar una serie de misiones que le permiten obtener claves secretas para lograr los retos que plantea el juego. Las aventuras de este héroe permitirán posteriores reconstrucciones narrativas de lo sucedido.

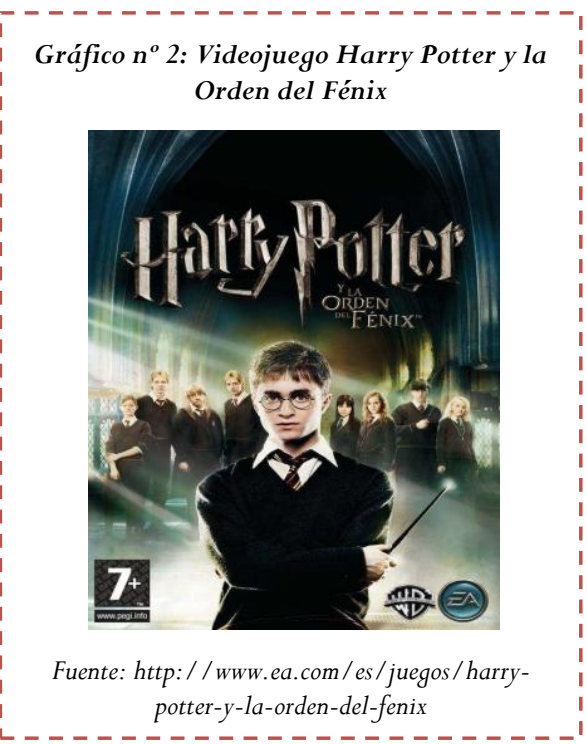

\section{Los talleres}

Los talleres objeto de esta investigación tuvieron lugar en un Instituto de Educación Secundaria de la Comunidad de Madrid. Un equipo de 10 investigadoras e investigadores de la Universidad de Alcalá y la UNED han participado junto al profesorado del centro y los estudiantes. Fueron varios los talleres y actividades realizadas en el Instituto con más de 300 alumnos. Participaron 17 grupos de clase de forma rotativa durante todo el curso, pero solo nos centraremos en el taller desarrollado con dos grupos: el curso de $4^{\circ} \mathrm{ESO}$ (A y B) en Bilogía y de $1^{\circ}$ ESO (A y B) en Lengua y Literatura, ambos en el tercer trimestre del 
curso. Los talleres se llevaron a cabo en un aula de informática que se convirtió en un salón de juegos. Distribuidas por el aula se colocaron varias consolas o PC's en función del taller, junto con los monitores y mandos.

Cuadro $n^{\circ}$ 1. Organización de los talleres

\begin{tabular}{|l|l|l|} 
ASIGNATURA & Biología & $\begin{array}{l}\text { Lengua y } \\
\text { Literatura }\end{array}$ \\
\cline { 2 - 3 } GRUPO & $\begin{array}{l}4^{\circ} \text { ESO } \\
\text { A y B }\end{array}$ & $\begin{array}{l}1^{\circ} \text { ESO } \\
\text { A y B }\end{array}$ \\
\cline { 2 - 3 } VIDEOJUEGO & Spore & $\begin{array}{l}\text { Harry Potter y } \\
\text { la Orden } \\
\text { del Fénix }\end{array}$ \\
CONSOLA & PC & Nintendo Wii \\
$\mathbf{N}^{\circ}$ SESIONES & 4 sesiones & 5 sesiones \\
\hline
\end{tabular}

Fuente: Informe de investigación: Videojuegos en el Instituto: Ocio digital como estímulo en la enseñanza (Lacasa \& GIPI, 2009)

Un aspecto esencial en esta experiencia, es el hecho de trabajar en estrecha colaboración con el profesorado y el papel de los investigadores en la definición del programa docente de las materias, cuando los videojuegos comerciales diseñados para el ocio, se convierten en instrumentos mediadores de las situaciones educativas en las aulas. Para ello, previo a las sesiones del taller y durante el desarrollo del mismo, se llevaron a cabo reuniones donde investigadores y docentes fueron definiendo los objetivos didácticos que se trabajarían y la metodología que se iba a emplear.

\section{¿Cuál era el ambiente de trabajo que} se originaba en el aula? Predominaba un trabajo cooperativo en pequeño y gran grupo. Donde adultos y adolescentes parti- cipaban activamente compartiendo los descubrimientos y aprendizajes producidos durante los momentos de juego y reflexión, favoreciendo así el diálogo. Las estrategias educativas de las personas adultas no solo se orientan a los aspectos procedimentales del videojuego, sino también a provocar la abstracción más allá de lo que aparece en las pantallas. Podemos distinguir durante todo el proceso de trabajo en el aula, la presencia de varios momentos: jugar, pensar y dialogar. Dichas fases se presentarían de forma constate a lo largo de todas las sesiones de trabajo, pues siempre surgían cosas nuevas sobre las que investigar en el juego y por tanto, ello requería de un momento de reflexión por parte del docente ante las nuevas cuestiones planteadas. El trabajo iba evolucionando a lo largo del proceso, adaptándose a las necesidades de los jugadores para avanzar en el juego y a la estrategia educativa del profesor.

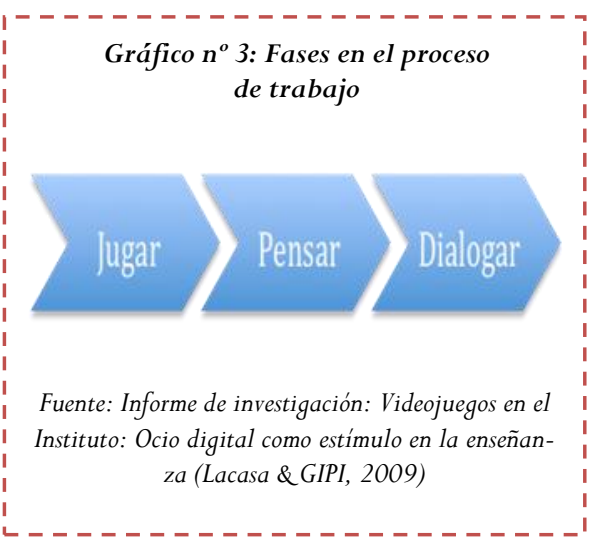




\section{Nuevas alfabetizaciones y videojuegos: el papel del profesor}

\begin{abstract}
"Nunca antes habíamos tenido tantos y tan buenos recursos a nuestro alcance para afrontar los problemas de las aulas, de los centros y de los sistemas educativos con el fin de mejorar la educación de TODOS los ciudadanos, que en definitiva es la clave para el progreso de los pueblos. ¿Sabremos aprovechar esta oportunidad?" (Marquès Graells, 2005).
\end{abstract}

Como dice Marquès, nunca antes habíamos tenido tantos y tan buenos recursos, la clave está en saberlos transformar en instrumentos educativos, tarea que recae directamente en los docentes. Por tanto, debemos explorar el aprendizaje y los procesos de alfabetización que se desarrollan cuando las personas forman parte de prácticas sociales, utilizando herramientas y tecnologías que manejan en los momentos de ocio, como es el caso los videojuegos comerciales (Singer, 2005). Según Lacasa (2006), resulta un reto permanente cuando se explora el papel de la tecnología como un instrumento de alfabetización. En esta línea, la escuela necesita reflexionar sobre cómo afectan esos universos digitales implicados en la vida de los jóvenes y los niños, con el fin de desarrollar nuevas formas de alfabetización (Gee, 2007).

Los trabajos de Gee (2004) pueden servir de referente en este proceso. Para este autor, cuando la gente aprende a jugar con videojuegos está aprendiendo un nuevo alfabetismo. El proceso de alfabetización no se produce de forma espontánea o aislada en el salón de casa o en cualquier otra situación de aprendizaje digital, sino que hay diversos agentes que influyen en que ese proceso se produzca. La presencia de instrumentos que ofrecen al individuo la adquisición de nuevas habilidades suponen un elemento clave en el proceso (como en este caso los videojuegos), pero es del todo necesario destacar otros agentes, como es el papel que el docente desempeña en ese entramado mediando entre el niño y el proceso educativo (Lacasa, 2011).

Estos cambios metodológicos, que pueden derivarse del acceso universal a la información y a la comunicación que proporciona Internet y otros medios, en el marco de una cultura colaborativa e integradora, son tan importantes que nos permiten dibujar un nuevo paradigma para los modelos de enseñanza y aprendizaje (Buckingham, 2003). En este sentido, el docente deberá analizar qué características y posibilidades ofrecen este tipo de medios, en este caso los videojuegos, para ver cómo transformarlo en un recurso educativo. 


\subsection{Estrategias educativas. Videojuegos en el aula}

"Dame una estrategia adecuada y alcanzaré cuanto deseas. Las estrategias son el punto de apoyo y la palanca para alcanzar objetivos y producir cambios". (De la Torre et al. 2003-2004, 71)

Cuando hablamos de estrategias educativas, nos estamos refiriendo a las acciones o propósitos del profesor a partir de las propias cualidades del medio que va a utilizar, en este caso el videojuego. El docente, por tanto, definirá sus propósitos en función del objetivo didáctico a alcanzar en relación con el contenido curricular y las posibilidades propias que definen al juego.

El proceso de establecer estrategias didácticas, conlleva una serie de factores según De la Torre (2000). A continuación mostramos algunos de ellos en función del objetivo propuesto:

- Consideración teórica o perspectiva del conjunto de proceso. Nos estamos refiriendo a la función del docente para definir el por qué y para qué usar el videojuego en el aula. Estableciendo de esta forma sus metas y el uso apropiado de la herramienta.
- Estrategia flexible y creativa que da lugar a una secuencia adaptativa. Los docentes definen su meta u objetivo a partir del uso del juego y en relación a los contenidos curriculares, diseñando así una estrategia propia en función de sus intereses.

- El papel de los Agentes o personas implicadas en el proceso de aprendizaje. En este proceso se presentan varios agentes, el instrumento (videojuego), el docente y sus metas, y los alumnos. Tan importante es la estrategia seguida por el docente para tratar de aplicar los contenidos curriculares al uso del videojuego, como las reflexiones alcanzadas por los alumnos que consiguen conectar ambos puntos.

Como podemos ver, la presencia de los videojuegos en las aulas puede resultar interesante debido a las cualidades y habilidades de aprendizaje que el alumnado puede desarrollar. Siempre y cuando el docente sea capaz de construir entornos de aprendizaje donde sus alumnos puedan descubrir y explorar. Por tanto, uno de los retos del profesorado es saber utilizar de forma provechosa el potencial que esconden estas herramientas. 


\section{Estrategias docentes y videojuegos: Cómo trabajar en el aula}

Como se ha expuesto anteriormente, es importante que el docente realice un proceso de reflexión respecto a las ideas y objetivos educativos que quiere alcanzar antes de introducir el videojuego en el aula. Teniendo en cuenta la actitud de experto que los alumnos suelen mostrar en relación a estos medios y las metas que el docente ha definido previamente, surge un espacio en relación al videojuego, donde dialogar y colaborar en la construcción del conocimiento.

Este contexto de diálogo permite al docente establecer un punto de partida de la situación educativa en el saber del alumnado y, a través de la reflexión y la crítica, diseñar los caminos más apropiados para acercar el currículum a los contenidos del videojuego. En este proceso, es importante que el docente sea capaz de trasladar la acción puramente lúdica (de la que parten los alumnos) a una situación de reflexión (tras el juego), estableciendo así un distanciamiento que supera el efecto de "inmersión participativa” y que va a permitir transformar estos objetos culturales en transmisores de conocimiento. A continuación, mostraremos cómo este proceso fue desarrollado por cada uno de los profesores que participaron en los talleres en función de sus propósitos y los videojuegos em- pleados, Spore en Biología y Harry Potter en la clase de Lengua y Literatura.

\subsection{Spore: Aprendiendo Biología}

¿Cómo transformar el aula en un escenario educativo innovador? ¿Cuál es el medio más adecuado? ¿Cómo conectar con los contenidos curriculares? ¿Cómo trabajar en el aula? Estas son algunas de las preguntas que la profesora se planteó con la intención de transformar su proceso de enseñaza-aprendizaje.

En este proceso de cambio, Spore se convirtió en un recurso de interés para trabajar los contenidos curriculares de la asignatura. Lo primero de todo, la docente definió el objetivo que pretendía alcanzar. Para ello, comenzó explicando las Teorías de la Evolución, antes de introducir el videojuego, de esta forma el alumnado podrían relacionar los contenidos aprendidos con el juego. A través del diálogo en pequeños grupos, los adolescentes serían capaces de establecer relaciones entre los conceptos teóricos que están inmersos en el videojuego y las teorías científicas en relación a la Teoría de la Evolución. Veamos en el siguiente ejemplo, cómo trabajaron en el aula. 
Fragmento 1. Relaciones entre el videojuego y las teorías de la evolución.

Sesión 1, 4 de Mayo 2009

Prof.: A ver empezamos por el grupo 3, a ver qué tiene (el videojuego) de cada teoría según vosotros.

Alum.: El más fuerte sobrevive Darwin.

Prof.: El más fuerte sobrevive de Darwin. ¿Es siempre más fuerte el que sobrevive? ¿Siempre es el más fuerte? ¿Hay otra manera de sobrevivir?

Alum.: Luego adaptación al medio de Lamarck y la de cooperación de Kimura.

Prof.: Y epor qué dices adaptación al medio de Lamarck?

Alum.: Porque tiene que ir mejorando en cada generación para que pueda sobrevivir mejor... Como lo de la jirafa, que cada vez tiene el cuello más largo para comer las cosas más altas, por ejemplo, el nuestro tiene cada vez la boca más distinta para poder comer enemigos cada vez más grandes.

Este fragmento muestra una situación donde los alumnos y alumnas reflexionaron en gran grupo apoyados por la docente. Como se puede observar, a partir del videojuego surgen referencias a los contenidos de la materia. Los estudiantes buscan y argumentan sus ideas en relación a las teorías evolutivas implícitas en las decisiones que han tomado durante la partida. Son capaces de argumentar qué es lo característico de cada una de las teorías expuestas en clase y lo relacionan con lo ocurrido en el momen- to del juego. Esta situación muestra cómo el videojuego se puede transformar en un instrumento que permite profundizar en contenidos curriculares y donde el papel del docente resulta ser un apoyo fundamental para desarrollar el pensamiento del alumnado.

Gráfico $n^{\circ}$ 4: Alumnado jugando con Spore

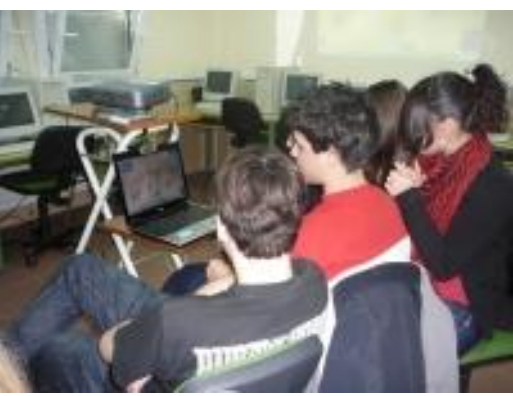

Fuente: Informe de investigación: Videojuegos en el Instituto: Ocio digital como estímulo en la enseñanza (Lacasa \& GIPI, 2009)

Sin olvidar que nuestra meta en esta investigación es la de mostrar la estrategia educativa seguida por la profesora para conectar videojuegos y contenidos curriculares, podemos ver otro ejemplo donde la docente no se conforma con que los alumnos y alumnas relacionen la teoría con el contenido del juego, sino que va un paso más allá intentando hacerles tomar conciencia de las consecuencias que tienen esas teorías en la práctica del videojuego. 
Fragmento 2. La lógica de las decisiones.

Sesión 1, 4 de Mayo 2009

Alum.: Sí, nosotros por ejemplo, le habíamos puesto una especie de aletas de velocidad en medio del cuerpo y no comía nada y las hemos puesto detrás y sí corrían.

Prof.: Eso qué significa? Es decir, tiene su lógica física el videojuego, ¿no?

Alum.: Sí, porque es lógico que atrás corra más.

Prof.: O sea que está bien pensado en este sentido.

Como se puede observar, el jugador emplea sus estrategias pensando en las ventajas que tendrá a la hora de avanzar en los estadios de evolución de la criatura. La presencia adulta les ayuda a ser conscientes de las estrategias utilizadas y de cómo ha influido esa elección en la adaptación al medio, a reflexionar sobre las diferentes opciones que ofrece el juego y ayudándoles a tomar conciencia de la necesidad de cambiar aspectos de sus criaturas que les hiciera ser más rápidos. Este ejemplo muestra cómo los alumnos realizando inferencias, aprenden a pensar.

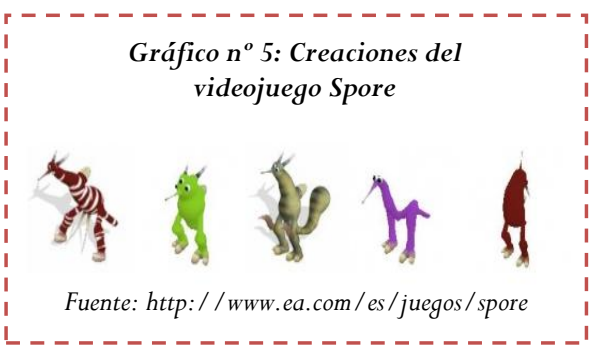

Podemos concluir que en este caso la docente en un primer momento seleccionó los contenidos que quería transmitir y posteriormente buscó el recurso más adecuado para trabajarlos, revelándose el videojuego Spore como un instrumento de gran interés para este proceso. Una vez introducido el juego en el aula, los alumnos aplicaron sus conocimientos teóricos previos en el diseño de las estrategias a seguir, a la hora de enfrentarse a los problemas planteados. Y la docente conectaría esas decisiones tomadas por los alumnos, con las teorías de la evolución a través del diálogo. Generando en éstos la reflexión y "toma de conciencia" de los conocimientos teóricos aprendidos a partir de la "puesta en práctica" a través del juego.

\subsubsection{Harry Potter: Contando historias}

Tras ver lo que ocurría en el aula cuando se introducía el videojuego Spore en la asignatura de Biología, es momento de ver qué sucedió cuando se introduce el juego Harry Potter y la Orden del Fénix en la clase de Lengua y Literatura. A diferencia de la profesora anterior, este docente se convirtió en jugador experto. Este hecho le permitió enfrentarse al videojuego y diseñar una estrategia educativa diferente, tomando como punto de partida tanto su objetivo curricular, como las cualidades que presentaba el juego elegido. Partiendo de esta visión, el siguiente fragmento 
muestra cómo introduce dicho medio en el aula.

Fragmento 3. Introducción del videojuego en el aula.

Sesión 1, 5 de Mayo 2009

Prof:: Os voy a dar a cada grupo una hoja con las misiones que tenéis que realizar, ¿vale? (...) El principio tiene que ser un descubrimiento, pero después de que hayamos descubierto cómo se maneja la varita y cómo nos situamos en el mapa del merodeador (...) nos vamos a situar en el mapa en lugares determinados, ¿para qué? Si no lo hacemos, Harry Potter y sus amiguetes tiene que estar toda la partida corriendo, y no tienen tiempo.

Prof.: Necesitamos que Harry Potter y sus amigos vayan lo más deprisa posible a los objetivos. Las tareas se relacionan con la búsqueda de 38 personajes. Cuanto más rápido lo consigamos, más posibilidad tendremos de hacer tan solo 4 sesiones (...) y llegar a la batalla final.

En estas palabras podemos observar cómo el profesor comienza explicando a sus alumnos la meta del juego, con el fin de que éstos pudiesen enfrentarse a ella de la forma más eficaz. En este caso, la meta del docente era que los alumnos avanzaran en el juego lo máximo posible a través de la resolución de problemas. Este hecho le permitió definir un poco más su objetivo y ser consciente que la historia del videojuego le podía permitir también trabajar los formatos textuales, la narración, la des- cripción y el diálogo, todo ello en relación con la escritura.

Gráfico ${ }^{\circ}$ 7: El profesor y el alumnado frente al videojuego Harry Potter y la Orden del Fénix

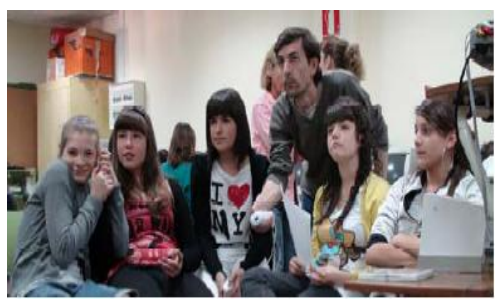

Fuente: Informe de investigación: Videojuegos en el Instituto: Ocio digital como estímulo en la enseñanza (Lacasa \& GIPI, 2009)

Fragmento 4. Objetivo del profesor con el videojuego.

Audio entre los investigadores y el profesor. Sesión 2, 12 de mayo 2009

Prof:: Lo que yo he buscado con el juego y la actividad, me da igual haber llegado, es que tengan todas las tareas disponibles y que vayan realizándolas. Quizás a mi ahí me dé más juego, para yo coger el libro, la película, hacer los cortes, porque aún no la he podido ver, pero esta semana a ver si la puedo ver y te mando los cortes. (...)

Prof.: La cosa está en que yo a partir de ahora voy a dar en el temario cosas relacionadas con la escritura, es decir, la narración, la descripción, el diálogo, y luego el tema el último tema que va a ser la literatura.

Como se observa en el ejemplo, el profesor parte de la resolución de problemas (ca- 
racterística propia de este tipo de medios) para llegar a su meta docente. Pretendía que su alumnado avanzase al máximo en la aventura y así poder construir historias sobre cómo se habían enfrentado a los diferentes retos. Descubriendo de esta forma cómo Harry se convierte en un personaje que enseña no sólo a analizar las situaciones para resolverlas, sino que permite a los jugadores reconstruir la historia que han vivido. Centrándose en este interés, de contar y escribir, que como profesor de Lengua y Literatura tenía, decide proponer a los alumnos la posibilidad de crear un periódico. Donde los estudiantes, basándose en sus vivencias en el juego, contarán sus aventuras o describirán a sus personajes. De esta forma, el profesor fue perfilando su objetivo a medida que tanto él como los alumnos y alumnas avanzaban en el juego.

Veamos ahora cómo lo vivió el alumnado a través de sus textos, concretamente los titulados "Artículos de opinión: la Wii en el aula”, donde revelan qué aspectos les gustaron más del taller y qué aprendieron.

Fragmento 5. El taller de videojuegos y la clase de lengua.

Producto. Artículo de opinión. Denise Bafuidinsoni

La experiencia ha consistido en que debíamos jugar a un juego de la wii, "Harry Potter". y hacer aparte algunas actividades literarias y educativas. Principalmente lo que hacíamos era que al llegar a la sala, el profesor nos entregaba una hoja donde aparecían escritos los objetivos que debíamos realizar y alcanzar durante ese día. (...)

Me ha parecido una actividad muy educativa porque, aparte de jugar, luego en clase hacíamos actividades con textos de Harry Potter y los analizábamos literariamente. También nos ha enseñado a trabajar en equipo y a conocernos más.

$\mathrm{Al}$ analizar este artículo de opinión, descubrimos que los estudiantes han puesto en práctica todos los conocimientos adquiridos durante la clase de lengua en su aula habitual, como se ve reflejado por Denise en este fragmento. Vemos que realmente el profesor consiguió convertir al videojuego en una herramienta de aprendizaje literario, por tanto su estrategia parte de jugar con el videojuego para trabajar a partir de él.

En este otro caso, a diferencia del anterior, se muestra una forma distinta de usar el videojuego partiendo de otras estrategias educativas. El profesor de lengua y literatura hace uso de las cualidades propias de este juego de aventuras, avanzando en su trama resolviendo múltiples tareas, que abrirán su mente para realizar posteriores narrativas como si fueran verdaderos escritores. 


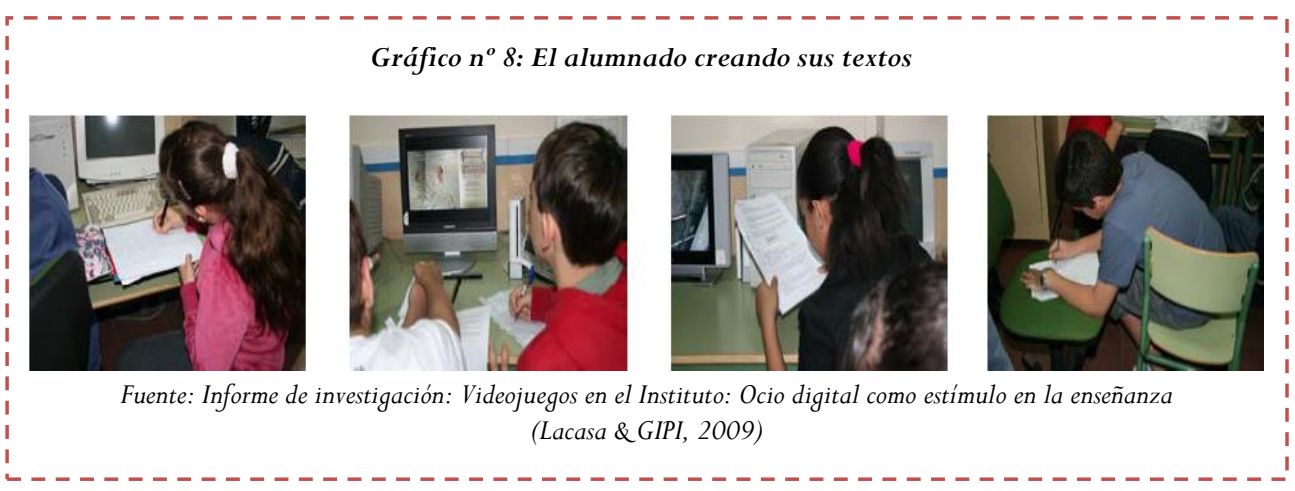

\section{Conclusiones}

La introducción de los videojuegos en las aulas ha supuesto cambios relacionados, por una parte, con la creación de escenarios educativos innovadores $\mathrm{y}$, por otra, con el aprendizaje de procesos de alfabetización digital. En este artículo se ha mostrado cómo los videojuegos con ayuda del docente, pueden convertirse en instrumentos educativos. La clave no es tanto el instrumento en sí, sino las relaciones que se establecen entre el contenido del mismo, los usuarios y los diálogos que se generan y son digiridos por la persona adulta.

El alumnado no necesita que se le enseñe a manejar los mandos o se le indique lo que tiene que hacer en cada pantalla, pero necesita comprender lo que se esconde detrás de estos medios. Esta es la meta de la que partieron los docentes y que les llevo a conectar estas herramientas con los contenidos curriculares, transformando así a este medio en un recurso útil en el proceso de enseñanza-aprendizaje.
Teniendo en cuenta las ideas derivadas de este trabajo podríamos concluir entonces que:

- Los alumnos y alumnas han aprendido a justificar sus decisiones, han sido conscientes de la importancia de sus acciones puesto que tienen consecuencias, que les influirá a lo largo de toda la experiencia del juego.

- Cuando la presencia del adulto orientó el diálogo, los aprendices reflexionaron sobre la importancia de los problemas y cómo habían abordado la resolución de los mismos para superarlos.

- Con la ayuda del adulto, los adolescentes son capaces de reflexionar y descubrir las estrategias que utilizan en el juego y sobre por qué la utilización de cada una de ellas generará diferentes opciones para superar los retos.

- El diálogo generado tras jugar al videojuego, permite a los chicos y chicas 
comprender y vivir la historia de lo que ha ocurrido.

Para finalizar, destacar que todos los videojuegos poseen un lenguaje, unas reglas y unas normas que les dan forma, un contexto donde el jugador forma parte activa enfrentándose a la trama del juego. Pero en ocasiones, el jugador requiere de una serie de recursos que faciliten avanzar en la par- tida. Nos estamos refiriendo a la importancia que tiene la narrativa del videojuego y su posterior reconstrucción a través del diálogo compartido en el aula. ¿Qué valor poseen estos instrumentos? Depende del uso que las personas hagan de ellos y de cómo su influencia facilite o no la adquisición de habilidades y nuevos aprendizajes.

\section{Referencias}

ATKINSON, P., COFFEY, A., DELAMNONT, S., LOFLAND, J., LOFLAND, C. \& Eds. (2001). Handbook of ethnography. London: SAGE.

BUCKINGHAM, D. (2003). Literacy, learning and contemporany culture. London: Polite Press.

CASTANHEIRA, M. L., CRAWFORD, T., DIXON, C. N. \& GREEN, J. (2001). Interactional ethnography: an approach to studying the social construction of literacy practices. Linguistics \& Education, 11(4), 353-400.

DE LA TORRE, S., OLIVER, C., VIOLANT, V., TEJADA, J., RAJADELL, N., \& GIRONA, M. (2003-2004). El cine como estrategia didáctica innovadora. Metodología de estudio de casos y perfil de estrategias docentes. Contextos educativos, 6-7, 6586.

GEE, J. P. (2007). Good Video games+ good learning. Collected essays on video games, Learning and Literacy. New york: Peter Lang.

GEE, J. (2005). An introduction to discourse analysis theory and method. U.K. Routledge.

GEE, J. P. (2004). Lo que nos enseñan los videojuegos sobre el aprendizaje y el alfabetismo (J. M. Pomares, Trans.). Málaga: Ediciones Aljibe.

HAMMERSLEY, M., \& ATKINSON, P. (2007). Ethnography: Principles in practice. USA \& Canada: Routledge.

KUHN, D. (2005). Education for thinking. Cambridge, Massachusetts: Harvard.
LACASA, P. E. (2006). Aprendiendo periodismo digital. Historias de pequeñas escritoras. Madrid: VisorAntonio Machado.

LACASA, P. (2011). Los videojuegos. Aprender en mundos reales $y$ virtuales. Madrid: Morata

LACASA, P. \& GIPI. (2009). Videojuegos en el Instituto. Ocio digital como estímulo en la enseñanza Informe de investigación. http: / / www.aprende yjuegaconea.com/files/informe_UAH_2009.pdf Acceso 20 enero 2011. Madrid. Electronics Arts de España y Universidad de Alcalá.

LACASA, P. \& GIPI. (2007). Aprendiendo con los videojuegos comerciales. Un puente entre ocio y educación. http: / / www .aprendeyjuegaconea.com /files/informe UAH 2007.pdf Acceso 20 enero 2011. Madrid. Electronics Arts de España y Universidad de Alcalá.

MARQUĖS, P. (2005). Las TIC y sus aportaciones a la sociedad. Didáctica y Multimedia, (Facultad de Ciencias de la Educación de la Universidad Autónoma de Barcelona). Retrieved from http//dewey.uab.es/ pmarques/tic.htm

SINGER, D. G., \& SINGER, J. L. (2005). Imagination and play in the electronic age. Cambridge, Massachusetts: Harvard university press. 
Cita de este artículo

GARCÍA PERNÍA, Ma R.; CORTÉS GÓMEZ, S. y MARTíNEZ BORDA, R. (2011) De los videojuegos comerciales al currículum: Las estrategias del profesorado Revista Icono14 [en línea] 1 de julio de 2011, Año 9, Volumen 2. pp. 249-261. Recuperado (Fecha de acceso), de http://www.icono14.net 